\title{
ARTICLE \\ A Sociopsychological Approach to Millennials Attitudes on Social Networking Sites
}

\author{
Dina El-Shihy ${ }^{1 *}$ Tamer Awad $^{2}$ \\ 1. NewGiza University, Egypt \\ 2. German University in Cairo, Egypt
}

Received: 6 January 2022; Accepted: 18 January 2022; Published: 19 January 2022

\begin{abstract}
This research aims to identify the social and psychological origins of needs, which may result in the need to obtain certain gratifications from social networking sites, different patterns of social networking sites usage, or cause social networking sites addiction, and the possible consequences they may have on millennials social capital and attitudes toward social networking sites advertising. The study adopts the Uses and Gratifications theory and employs a quantitative research method. The sample of the study consisted of 385 millennials, aged from 21-37 years old, who all used Facebook, Instagram, and YouTube platforms. Data were analyzed using the Structural Equation Modeling. The findings of the study provide useful insights regarding millennials behavior on social networking sites, as well as their attitudes towards social networking sites advertising. The findings suggest several implications and recommendations for marketers, which can help in increasing the effectiveness of advertisements directed to millennials.
\end{abstract}

Keywords: Social networking sites, Sociopsychological traits, Attitudes, Social networking sites advertising

\section{Introduction}

The advancements in communication technologies have shifted the way individuals interact to viral means instead of direct communications. Social networking sites (SNS) are one type of social media ${ }^{[1]}$, which has largely impacted individuals' daily lives. Individuals engage in SNS for various reasons that range from private chatting, socialization, timeline posts and professional networking. SNS benefits individuals, young entrepreneurs, organizations, companies, and institutions as well ${ }^{[2]}$.
However, besides these benefits, SNS addiction has become a concern ${ }^{[3]}$, because despite its advantages, it has also been connected to a variety of problems ${ }^{[4]}$, and public awareness has been rapidly growing with regards to the potential adverse effects that may result from its mal-adaptive and excessive usage ${ }^{[5]}$.

\subsection{SNS Addiction}

These technological advancements have rapidly increased individuals' usage, which have accordingly

*Corresponding Author:

Dina El- Shihy,

NewGiza University, Egypt;

Email: Elshihy.dina@ngu.edu.eg

DOI: https://doi.org/10.54963/dtra.v1i1.30

Copyright (C 2022 by the author(s). Published by UK Scientific Publishing Limited. This is an open access article under the Creative Commons Attribution (CC BY) license (https://creativecommons.org/licenses/by/4.0/). 
been reported to cause dependence and addiction. SNS addiction has similar characteristics of other substances addiction, such as alcohol and drug addictions [6]. Previous research indicated that substance dependence and addictions include criteria such as a reduction and impairment in the social, academic, and recreational activities. SNS addiction, which is a subtype of technology addiction, can result in the experience of negative personal repercussions, such as vitality and decreased happiness, social isolation, obesity, alterations in mood, social inhibition, and a decreased performance at school or work ${ }^{[7]}$.

Preceding studies examined internet addiction from diverse perspectives and using various research questions and hypotheses. However, most of the studies either examined internet addiction, online game addiction ${ }^{[8,9]}$, or social media in general ${ }^{[10-12]}$. It is suggested that each type of social media has its own usage; in terms of its social consequences, the communications that it facilitates and the rewards it has for its users ${ }^{[13]}$. In addition to that, there has been a dearth in literature and research related to different types of SNS, as well as the consequences of their excessive usage ${ }^{[14]}$.

While the number of individuals using SNS increases and the frequency of their SNS usage increases, the number of victims of such excessive usage increases as well. Therefore, it becomes necessary to investigate the consequences of excessive SNS usage and understand related deviant behaviors, which subjects SNS addiction to further research and investigation ${ }^{[6]}$.

\subsection{Uses and Gratifications Theory}

The Uses and Gratifications theory (U\&G) has been used for more than 60 years to answer such questions of why people use a specific medium and the reasons behind their usage. This theory assumes that individuals choose certain media and content to satisfy their needs. The U\&G theory explains the psychological and social needs that motivate individuals to engage in media usage ${ }^{[15]}$. For scholars, theoretically and practically, the basic concern remains to be why individuals become involved in a specific medium and what gratifications they obtain from it ${ }^{[16]}$.

As the usage of social media continues to increase, it becomes more important for researchers to gain a better understanding of the reasons that motivate users to use such platforms ${ }^{[17]}$. Especially since it is argued that individuals do not get addicted to one medium per se, but they get addicted to certain activities that they carry out online ${ }^{[18]}$. As SNS continues to attract a huge number of new and existing members daily, and as individuals' SNS usage continues to increase, user motivations to participate in SNS, and the resulting gratifications and rewards, represent fertile ground for further investigation ${ }^{[19]}$. Accordingly, the study aims to explore how can the gratifications obtained from SNS predict SNS usage among millennials, through the following hypothesis:

H1: Millennials who are more gratified by SNS are more likely to engage in higher SNS usage.

Research has linked gratifications to addiction, and gratifications individuals obtain from a certain medium, play different roles in the determination of their addiction tendency. Gratifications obtained are suggested to result in repeated media usage and psychological reinforcement, which might result in dependence. Individuals become dependent on something for the psychological reinforcement and satisfaction that it provides ${ }^{[20]}$. Based on this analysis, it can be assumed that users who engage in higher SNS usage, or obtain more gratifications from SNS, have a greater possibility of becoming addicted. Hence, to explore how can gratifications obtained and SNS usage predict SNS addiction among millennials, the following hypotheses are formulated:

H2.1: Millennials who engage in higher SNS usage are more likely to become addicted to SNS.

H2.2: Millennials who are more gratified by SNS are more likely to become addicted to SNS.

\subsection{Sociopsychological Traits}

Although sociopsychological factors are considered a vital factor that affects SNS usage and individuals' behaviors, very little data are available on the adoption of SNS, with respect to sociopsychological factors, and very limited attention has been given to how these factors may contribute in deviant behaviors or SNS addiction. It is important to explore the influence of different sociopsychological traits on SNS usage and adoption, and how they involve users in SNS addiction. Social psychology research identified the most important social and psychological traits that affect individuals' motivations and behaviors ${ }^{[21]}$.

This study introduces two social traits: need for affiliation ${ }^{[22]}$, and impression management ${ }^{[23]}$, as well as two psychological traits: narcissism ${ }^{[24]}$, and leisure boredom ${ }^{[25]}$.

\subsubsection{Need for Affiliation}

All humans desire a minimum amount of healthy relationships with others, and their means to maintain such relationships can be reflected in their frequent social contact with others. Need for affiliation reflects an individual's desire for belongingness and social contact and refers 
to the ability of an individual to derive pleasure from friendly or close relationships with others ${ }^{[26]}$. Individuals with strong need for affiliation seek to engage in internet communication and intimate conversations with ease of self- disclosure, and perceive internet communication as more reciprocal, controllable, deeper, and broader than face-to-face communication ${ }^{[27]}$. Need for affiliation is one of the primary reasons that engage individuals in social media usage, since it grants them, their affiliation needs and develops their interpersonal relationships and social interactions ${ }^{[28]}$. However, this desire to affiliate may lead to maladaptive usage, which may result in addiction if taken too far ${ }^{[29]}$. Accordingly, to investigate how can need for affiliation predict gratifications obtained, SNS usage, and SNS addiction among millennials, the following hypotheses are developed:

H3.1: Millennials who have higher needs for affiliation are more likely to find SNS more gratifying.

H3.2: Millennials who have higher needs for affiliation are more likely to engage in higher SNS usage.

H3.3: Millennials who have higher needs for affiliation are more likely to become addicted to SNS.

\subsubsection{Impression Management}

It is in human nature that we spend a lot of time with other people, and our social behavior is influenced by understanding how others see us ${ }^{[30]}$. Impression management refers to an individual's effort to create, protect, maintain, or alter his/her image. Individuals use various impression management tactics and behaviors to create a desired image and to accomplish this goal ${ }^{[31]}$.

To appear to others as a decent and acceptable person, individuals usually try to manage the impressions they give and present themselves in the way they would want to be seen by others. They try to project this self-impression and maintain it by consistently performing complementary and coherent behaviors. SNS environment erodes individuals' ability to custom a "unified" identity, since to interact with various people in the online environment, individuals may attempt to portray and reveal different personalities ${ }^{[1]}$. On SNS, self- presentation is easier to control than in face-to-face communication. SNS provides an ideal opportunity for impression management. Users have the capability to think about the aspects of personalities they want to present; they are more likely to strategically manage their self- presentations than in face-to-face situations ${ }^{[32]}$. Researchers have also found links between impression management, and higher social media usage, which may result in problematic social media usage as well, since it provides individuals with an environment to invoke positive self-presentation, manage their impressions and help many people project a better version of themselves on social media. To assess how can impression management predict gratifications obtained, SNS usage, and SNS addiction among millennials, the following hypotheses are developed:

H4.1: Millennials who are better at impression management are more likely to find SNS more gratifying.

H4.2: Millennials who are better at impression management are more likely to engage in higher SNS usage.

H4.3: Millennials who are better at impression management are more likely to become addicted to SNS.

\subsubsection{Narcissism}

Narcissism is the degree to which individuals are preoccupied with continuously reinforcing their self-view and have exaggerated sense of self ${ }^{[33]}$, believe they are special and unique, have a constant need for admiration, seek veneration from others, and are always engaged in self-centered behavior and thinking ${ }^{[34]}$.

A tremendous amount of attention has been given to the relation between narcissism and social media. Such online communities have been seen as a fertile ground for narcissists since they offer them a gateway for shallow relationships (i.e., virtual friends), and facilitate emotionally detached communication (i.e., comments and wall posts) ${ }^{[35]}$. Moreover, given that narcissists seek personal interaction, as a mean for self- promotion and self- enhancement; several attributes of SNS make them an ideal tool to achieve their narcissistic goals ${ }^{[36]}$.

Narcissism has increased among the digital native generations. According to prior research, social media are an ideal medium for attention-seeking narcissists, because they get to overstate their enjoyment of life and accomplishments, exaggerate their self- importance, and blatantly show off. Such narcissists tend to be the heaviest contributors and users of social media and are also the most likely to be addicted to such platforms ${ }^{[7]}$. To investigate how can narcissism predict gratifications obtained, SNS usage, and SNS addiction among millennials, the following hypotheses were developed:

H5.1: Millennials who are more narcissistic are more likely to find SNS more gratifying.

H5.2: Millennials who are more narcissistic are more likely to engage in higher SNS usage.

H5.3: Millennials who are more narcissistic are more likely to become addicted to SNS.

\subsubsection{Leisure Boredom}

Leisure behavior can be psychologically rewarding 
when individuals have the right amount of time for their leisure activities. However, young people with unstructured leisure activities are more prone to feelings of boredom ${ }^{[37]}$.

Leisure boredom has caused an alarm and has gained the attention of many scholars, since it was related to different forms of addiction, extreme sensation activity, smoking, delinquency, drug, and alcohol abuse. The netgeneration easily encounter boredom, and accordingly, participate in different activities to prevent it. The advancement of electronic media, such as computer/ video gaming and internet/ web surfing, have occupied most of young people's leisure time. Social media have also occupied most of young people's leisure time and greatly displaced other types of social activities ${ }^{[38]}$. It is argued that individuals who encounter high levels of leisure boredom are more likely to become engaged in social media and are more likely to become addicted to them ${ }^{[39]}$. To explore how can leisure boredom predict gratifications obtained, SNS usage, and SNS addiction among millennials, the below hypotheses were developed:

H6.1: Millennials who are more leisurely bored are more likely to find SNS more gratifying.

H6.2: Millennials who are more leisurely bored are more likely to engage in higher SNS usage.

H6.3: Millennials who are more leisurely bored are more likely to become addicted to SNS.

\subsection{Social Capital}

Social capital refers to the benefits individuals derive from their social interactions and relationships, including emotional support, access to non-redundant information, and exposure to different ideas ${ }^{[40]}$. It is the connections people make to boost their community standing, enhance themselves and their wellbeing ${ }^{[4]}$. Social capital is an important motivation for individuals in the virtual community and plays an important role in shaping users' social behaviors ${ }^{[14]}$, when individuals feel uneasy and anxious in offline interactions, they usually flee to virtual sources of interactions ${ }^{[42]}$.

It is not the technology itself that affects individuals' social capital, but the ways in which it is used. Moreover, it is debated that since social capital is all about connections with people, individuals who use social networks heavily or are addicted to them may generate more social capital ${ }^{[43]}$. However, other studies argue that it may result in less social capital, since social networks occupy the time that could be used to meet up and bond with others in the offline world ${ }^{[44]}$.

The relationship between electronic-based social networks in shaping users' behaviors in the online and offline world, as well as the formation of social capital seems to be not quite clear in research literature ${ }^{[45]}$, and because of the increased popularity of SNS, and as individuals' offline social lives have been largely integrated with their online social lives, it becomes important to explore the effect SNS usage and addiction on their social capital ${ }^{[14]}$. To explore how can gratifications obtained, SNS usage, and SNS addiction predict millennials social capital, the following hypotheses are raised:

H7.1: Millennials who find SNS gratifying are more likely to have a larger social capital.

H7.2: Millennials who engage in higher SNS usage are more likely to have a larger social capital.

H7.3: SNS addicts are more likely to have a larger social capital than non-addicts.

\subsection{Attitudes towards SNS Advertising}

The rapid development of SNS has created a massive transition in the field of advertising. Since SNS enables individuals to interact, share their common interests, discuss, and share information and ideas, individuals can easily be influenced by advertisements that are related to their interests ${ }^{[46] .}$ As a result, advertisers have recognized the influence of this medium and started to utilize the opportunities it offers for business promotion. Today, SNS has become an essential medium for advertising, and marketers started spending a huge amount of effort on advertisements through this medium ${ }^{[47]}$.

Millennials, in specific, are considered a vital consumer group, since they provide an indication of future purchase tendencies toward certain products and service. Therefore, their perceptions of social media advertising communications are of great importance to companies ${ }^{[48]}$. Moreover, because of their high social media usage, social media are considered the most promising venue to reach this generation ${ }^{[49]}$. It becomes critical for marketers to try to engage with millennials and understand their attitudes toward social media advertising to make use of this medium as it expands ${ }^{[50]}$.

The majority of social media advertising research has been conducted in developed nations, especially in Europe and the United States, and little attention has been given to the developing economies; specifically, in Africa. It is suggested that consumers' attitudes, from dissimilar cultural backgrounds, are expected to differ ${ }^{[51]}$. Moreover, the influence of the amount of time individuals spend on SNS on their attitudes toward SNS advertising has still not been sufficiently addressed yet. Researchers also need to examine the influence of gratifications obtained from SNS on users' attitudes toward SNS advertising as well, to 
have a clearer understanding of what might be attractive and relevant for young consumers ${ }^{[52]}$.

Consumer acceptance is vital for SNS advertisers, and to understand the factors that affect attitudes toward SNS advertising, it is necessary to understand the attitudes of consumers toward advertising in general. Even though attitudes toward a specific advertisement can be influenced by other factors, the consumers' attitudes toward advertisements in general are more complex and more important to understand ${ }^{[53]}$, it has also been argued that users accept SNS advertisements that are consistent with their motivations to use SNS, and the time individuals spend on SNS, as well as SNS addiction are suggested to have an influence on their acceptance to these advertisements ${ }^{[54,55]}$. Accordingly, the following hypotheses are raised:

H8.1: Millennials who are more gratified by SNS are more likely to develop more positive attitudes toward SNS advertising.

H8.2: Millennials who engage in higher SNS usage are more likely to develop more positive attitudes toward SNS advertising.

H8.3: SNS addicts are more likely to develop more positive attitudes toward SNS advertising.

\section{Methods}

To achieve the research objectives and provide an inclusive understanding of SNS addiction in Egypt, the study adopted a quantitative research method using the convenience non-probability sampling technique, since most of the studies conducted on internet and social media addiction used this technique ${ }^{[56-60]}$.

The sample chosen was based on three main variables that were (1) the necessity of owning SNS profiles on Facebook and Instagram, (2) the necessity of using YouTube, and (3) the age interval (millennials; from 2137 years old). Respondents who failed to meet these three criteria were excluded in the selection process. The total number of valid responses after data screening consisted of 385 millennials.

Prior to questionnaire distribution, the researcher conducted a panel study that consisted of three experts, where an academic, a marketeer, and a psychiatrist were requested to give their feedback to the questionnaire, based on their knowledge and areas of expertise, before distributing it to the whole sample. After conducting the panel study, the researcher conducted a pilot study, which consisted of 30 millennials, to find if there were any unclear questions or expressions, to avoid deficiencies, and improve the study's design, in preparation for the major study. Survey questions were modified according to the comments obtained from pretesting.

The measurement items that were used to operationalize the constructs of the study were retrieved from previous studies. Items were measured using a five-point Likert scale. The SNS Addiction items were based on ${ }^{[61]}, U \& G$ items were based on ${ }^{[62]}$, Sociopsychological traits items were based on ${ }^{[63]}$ scale for the Need for Affiliation items, ${ }^{[64]}$ scale for the Impression Management items, ${ }^{[65]}$ scale for Narcissism items, and ${ }^{[6]]}$ scale for Leisure Boredom

Sociopsychological Traits

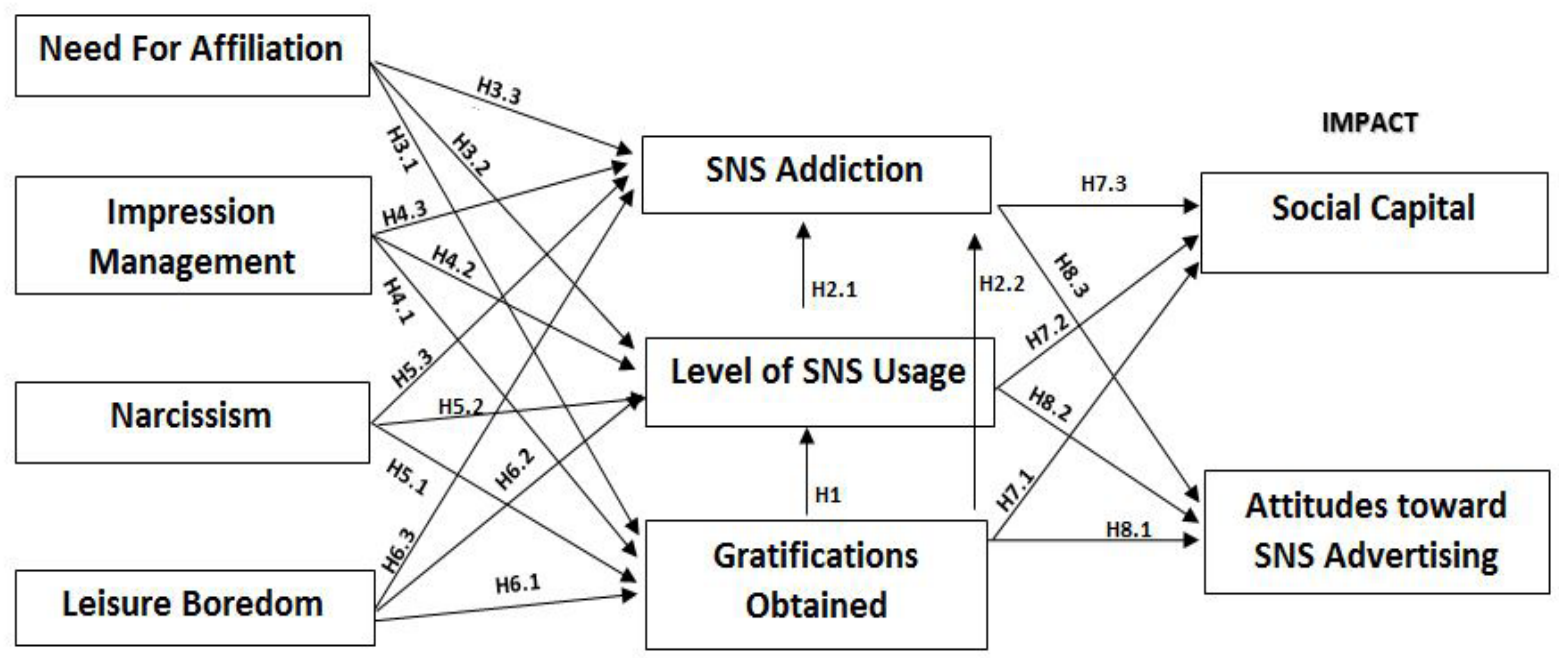

Figure 1. Conceptual Linkages of all variables 
items, Social Capital items were based on ${ }^{[67]}$ scale, and the attitudes toward SNS Advertising items were based on ${ }^{[68]}$ scale.

The Overall Internet and SNS usage were measured using three general close-ended questions, developed by the researcher, to measure the overall Internet and SNS usage, and to provide a better understanding of millennials behavior on SNS.

Results were then analyzed through the Structural Education Modeling (SEM) using Analysis of Moment Structures (AMOS 23.0).

\section{Results and Discussion}

SEM provides a powerful method to assess a structural model, because of its minimal demands on the measurement scales ${ }^{[69]}$, it provides, overall tests of model fit, and individual parameter estimate tests, simultaneously ${ }^{[70]}$. SEM goes beyond the ordinary regression models, as it incorporates both multiple independent and dependent variables, in addition to hypothetical latent constructs. It also tests the specified set of relationships among different observed and latent variables and allows theory testing even when experiments are not possible. Accordingly, these methods have become widespread in all behavioral and social sciences ${ }^{[71]}$.

\subsection{Measurement Model}

For SEM to be conducted, there must be no missing data ${ }^{[72]}$, a critical sample size of 200 is recommended, any number above 200 provides sufficient statistical power for data analysis ${ }^{[73,74]}$, constructs must be defined, through pretesting; to evaluate reliability and validity of the items ${ }^{[75]}$, and a correlation matrix should be obtained, to initially show that a correlation exists between the constructs ${ }^{[76]}$. Confirmatory tests should be conducted to measure if items have acceptable factor loadings for their respective latent constructs, and any items that have a low factor loading should be disregarded. After deleting the items with low factor loadings, the researcher can then run the model ${ }^{[77]}$.

Confirmatory Factor Analysis (CFA) was utilized as recommended by ${ }^{[78]}$; to assess and modify the proposed model. As suggested by ${ }^{[79]}$, the study examined multiple indices of model fit using multiple indices, including Minimum Discrepancy/Degree of Freedom (CMIN/DF), the Goodness of Fit Index (GFI), the Adjusted Goodness of Fit Index (AGFI), Normed Fit Index (NFI), the Comparative Fit Index (CFI), and the Root Mean Square Error of Approximate (RMSEA).

1) Reliability Testing: Reliability was tested using convergent reliability (average variance extracted), as well as construct reliability (or composite reliability). According to the generally acceptable analysis levels, construct reliability should be more than 0.7 and convergent reliability should be more than $0.5^{[80]}$. As shown in Table 1, all constructs indicated reliability.

2) Uni-dimensionality Testing: Table 2 provides a summary of the recommended values and benchmarks

Table 1. Constructs Reliability

\begin{tabular}{cccc}
\hline Constructs & Convergent Reliability (AVE) & Construct Reliability & Discriminant Validity \\
\hline SNS Addiction & 0.568 & 0.764 & 0.114 \\
Gratifications Obtained & 0.639 & 0.835 & 0.108 \\
Need for Affiliation & 0.622 & 0.831 & 0.205 \\
Impression Management & 0.652 & 0.849 & 0.093 \\
Narcissism & 0.516 & 0.665 & 0.108 \\
Leisure Boredom & 0.608 & 0.724 & 0.233 \\
Social Capital & 0.597 & 0.816 & 0.245 \\
Attitudes toward SNS Advertising & 0.568 & 0.764 & 0.114 \\
\hline
\end{tabular}

Table 2. Recommended Benchmark for Model Fit Indices

\begin{tabular}{cc}
\hline Indices & Indications of Model Fit Indices/ Recommended criteria \\
\hline CMIN/DF & A value close to 1 and not exceeding 3 indicates a good fit. A value less than 1 indicates an over-fit. \\
GFI & The GFI value is always less than or equal to 1 . A value close to 1 indicates a perfect fit. \\
AGFI & The AGFI value is bounded above by 1 and is not 0 . A value close to 1 indicates a perfect fit. \\
NFI & The NFI value lies between 0 and 1 . A value close to 1 indicates a very good fit \\
CFI & The CFI value is between 0 and 1 . A value close to 1 indicates a very good fit. \\
RMSEA & A value about 0.05 or less indicates a close fit of the model, 0.0 indicates an exact fit, about 0.08 or less indicates a reasonable error \\
of Approximation. A value should not be greater than 0.1
\end{tabular}


for the model fit indices ${ }^{[81]}$. As shown in Table 3, results indicate that there is no unidimensionality and all results indicated a good fit of the model.

1) Validity Testing: Validity was tested using Discriminant validity. Discriminant validity is the extent to which constructs are different or unrelated to each other ${ }^{[82]}$. Convergent reliability should be compared with the average shared variance and the value must be smaller than the value of the average. As shown in Table 1, all constructs indicated validity.

2) After that, Correlational Analysis was conducted to show that a correlation exists between constructs. Table 4 below summarizes the significant correlations between all constructs, $p<0.05$.

After conducting reliability, validity, and correlation analysis, and since the sample size of the study was 385 respondents; more than the minimal number of respondents required by SEM, the researcher was able to run the SEM analysis.

\subsection{Structural Equation Model}

After that, the researcher examined the items' path directions and significant levels from the standardized regression weight output. C.R scores that are larger than 1.96 are significant at $p<0.05$ level ${ }^{[83]}$. As shown in Table 5 , all C.R values are greater than 1.96 , which shows

Table 3. Goodness-of-fit Results for CFA Structural Model

\begin{tabular}{cccccccccc}
\hline Model & \multicolumn{10}{c}{ Goodness-of-fit Results } \\
\hline \multirow{2}{*}{ Final } & Chi-Square & P & CMIN/DF & GFI & AGFI & NFI & CFI & RMSEA \\
\cline { 2 - 10 } & 35.504 & 0.002 & 2.367 & 0.98 & 0.94 & 0.959 & 0.975 & 0.06 \\
\hline
\end{tabular}

Table 4. Summary of Significant Correlations between Constructs $p<0.05$.

\begin{tabular}{|c|c|c|c|c|c|c|c|c|c|}
\hline & $\begin{array}{c}\text { SNS } \\
\text { Addiction }\end{array}$ & $\begin{array}{l}\text { SNS } \\
\text { Usage }\end{array}$ & $\begin{array}{c}\text { Gratifications } \\
\text { Obtained }\end{array}$ & $\begin{array}{l}\text { Need for } \\
\text { Affiliation }\end{array}$ & $\begin{array}{c}\text { Impression } \\
\text { Management }\end{array}$ & Narcissism & $\begin{array}{l}\text { Leisure } \\
\text { Boredom }\end{array}$ & $\begin{array}{l}\text { Social } \\
\text { Capital }\end{array}$ & $\begin{array}{c}\text { Attitudes towards } \\
\text { SNS advertising }\end{array}$ \\
\hline SNS Addiction & & $\mathrm{X}$ & $\mathrm{X}$ & $\mathrm{X}$ & $\mathrm{X}$ & $\mathrm{X}$ & $\mathrm{X}$ & $\mathrm{X}$ & $\mathrm{X}$ \\
\hline SNS Usage & & & $\mathrm{X}$ & & & $\mathrm{X}$ & $\mathrm{X}$ & $\mathrm{X}$ & $\mathrm{X}$ \\
\hline Gratifications Obtained & & & & $\mathrm{X}$ & $\mathrm{X}$ & $\mathrm{X}$ & $\mathrm{X}$ & $\mathrm{X}$ & $\mathrm{X}$ \\
\hline Need for Affiliation & & & & & $\mathrm{X}$ & $\mathrm{X}$ & $\mathrm{X}$ & $\mathrm{X}$ & $\mathrm{X}$ \\
\hline Impression Management & & & & & & $\mathrm{X}$ & $\mathrm{X}$ & $\mathrm{X}$ & $\mathrm{X}$ \\
\hline Narcissism & & & & & & & $\mathrm{X}$ & $\mathrm{X}$ & $\mathrm{X}$ \\
\hline Leisure Boredom & & & & & & & & $\mathrm{X}$ & $\mathrm{X}$ \\
\hline Social Capital & & & & & & & & & $\mathrm{X}$ \\
\hline $\begin{array}{c}\text { Attitudes towards SNS } \\
\text { advertising }\end{array}$ & & & & & & & & & \\
\hline
\end{tabular}

Table 5. Standardized Regression Weights

\begin{tabular}{|c|c|c|c|c|c|c|}
\hline & & & Estimate & S.E. & C.R. & $\mathrm{P}$ \\
\hline Gratifications Obtained & $<---$ & Leisure Boredom & 0.091 & 0.065 & 2.241 & 0.025 \\
\hline Gratifications Obtained & $<---$ & Need for Affiliation & 0.218 & 0.054 & 5.113 & $* * *$ \\
\hline Gratifications Obtained & $<---$ & Impression Management & 0.266 & 0.057 & 5.973 & $* * *$ \\
\hline SNS Usage & $<---$ & Gratifications Obtained & 0.187 & 0.009 & 3.735 & $* * *$ \\
\hline SNS Addiction & $<---$ & Narcissism & 0.24 & 0.049 & 5.279 & $* * *$ \\
\hline SNS Addiction & $<---$ & SNS Usage & 0.297 & 0.159 & 6.599 & $* * *$ \\
\hline SNS Addiction & $<---$ & Gratifications Obtained & 0.22 & 0.03 & 4.756 & $* * *$ \\
\hline Social Capital & $<---$ & SNS Addiction & 0.13 & 0.065 & 2.989 & 0.003 \\
\hline Social Capital & $<---$ & SNS Usage & 0.141 & 0.223 & 3.325 & $* * *$ \\
\hline Social Capital & $<---$ & Gratifications Obtained & 0.971 & 0.107 & 8.789 & $* * *$ \\
\hline Attitudes toward SNS Advertising & $<---$ & SNS Usage & 0.16 & 0.155 & 3.351 & $* * *$ \\
\hline Attitudes toward SNS Advertising & $<---$ & Leisure Boredom & 0.246 & 0.046 & 5.092 & $* * *$ \\
\hline
\end{tabular}


the achievement of significance level, which confirms the convergent validity of the constructs of the study. Moreover, all paths were significant at a $99 \%$ confidence level.

Standardized regression weights allow the researcher to compare the effect of every independent variable on the dependent variable. Path coefficients were used to test the hypotheses of this study. The path coefficient analysis shows the direction and strength of the relationship between the independent and the dependent variables, the bigger the path coefficient, the stronger the relationship between variables. The significance tests are the basis for accepting or rejecting the proposed relationships between the constructs of the models ${ }^{[84]}$. Results of hypotheses testing are discussed below.

Results indicated that gratifications obtained significantly and positively affected the level of SNS usage $($ Path coefficient $=0.187, p$-value $=0.000 ; \underline{\text { H1 }}$ supported), results were consistent with the $U \& G$ theory that assumes that individuals engage in media to fulfill their own needs, and when an individual's expectations on social media grow and become obtained through such channels, their engagement and usage are more likely to grow and get affected as well ${ }^{[38]}$.

Results revealed that SNS addiction was significant with SNS usage (path coefficient $=0.297, p$-value $=0.000$; H2.1 supported), that was supported with preceding studies, individuals classified as internet addicts, use the internet more than non- addicts, and that the intensity of social media use indicates social media addiction. Individuals who frequently used the internet were more compulsive and dependent, they were also more likely to stay longer online and show internet addiction symptoms ${ }^{[55]}$. Results also revealed that SNS addiction was significant with gratifications obtained (path coefficient $=0.22, p$-value $=0.000 ; \underline{\mathbf{H 2} .2}$ supported $)$; since gratifications obtained from SNS can largely satisfy millennials needs, it is certain that they have a potential of leading to addiction. The most powerful predictors of addiction were the motives for relationship building, social, and communication gratifications ${ }^{[37,85]}$.

The results revealed that need for affiliation significantly and positively affected gratifications obtained (path coefficient $=0.218, p$-value $=0.000 ; \underline{\mathbf{H 3} .1}$ supported). Individuals with high needs for affiliation have the tendency to seek and acquire social gratifications, from seeking approval and connection with others, and hence, they can be gratified with social media, since it grants them with affiliation needs and enables them to get social with others ${ }^{[26]}$. However, results revealed that need for affiliation insignificantly affected the level of SNS usage (the initial study model revealed an insignificant association between variables and the model fit indices suggested removing the path between them; $\underline{\text { H3.2 }}$ rejected), and insignificantly affected SNS addiction (H3.3 rejected). Yet, individuals with a strong need for affiliation may prefer to engage with others through offline social activities and interactions, as they provide them with a stronger sense of belonging with others in the real world ${ }^{[86]}$.

The results indicated that impression management significantly and positively affected gratifications obtained from SNS (path coefficient $=0.266, p$-value

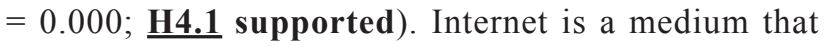
enables identity manipulation, or, at least, selective presentation of oneself, individuals engage in impression management tactics and present themselves in a positive way, by putting huge efforts in designing their profiles and presenting large numbers of friends, since they find them gratifying ${ }^{[87]}$. However, results revealed that impression management insignificantly affected SNS usage ( $\underline{\mathbf{H 4 . 2}}$ rejected) and insignificantly affected SNS addiction $(\underline{\mathbf{H 4 . 3}}$ rejected). Even though it has been argued that there was a positive relationship between impression management and social media usage ${ }^{[88]}$, however, it is also argued that some users are more competent than others in impression management tactics, the ones who are, are more likely to engage more in social media usage and are more likely to become addicted than others who are less competent. Moreover, individuals seeking long-term goals of establishing face-to-face relationships, have higher levels of self- disclosure. They try to present themselves the way they are, in a more realistic manner and tend to include both positive and negative attributes. This is because they understand that eventually, such attributes will be revealed, if they develop ongoing face-to-face relationships with these individuals ${ }^{[66,87]}$.

The results revealed that narcissism insignificantly affected gratifications obtained (H5.1 rejected). However, according to research, narcissists can be classified into grandiose narcissists and vulnerable narcissists. The vulnerable type has insecure or defensive sense of grandiosity, associated with low self- esteem, hypersensitivity to the evaluation of others, incompetence and inadequacy, inferiority, and high reactivity to evaluative events, unlike grandiose narcissists ${ }^{[89]}$. Based on that, it could be assumed that the narcissists of this study were of the vulnerable type, hence, were not gratified by SNS, since it opens room for others evaluation, comments, and criticism. Results indicated that narcissism also insignificantly affected millennials SNS usage ( $\underline{\mathbf{H 5} .2}$ rejected). According to ${ }^{[90]}$, millennials 
social media usage is not only related to maintain their self-esteem, attention seeking and narcissistic motives, but it is to primarily communicate with others and stay connected with them. Surprisingly, results revealed that narcissism significantly affected SNS addiction (path coefficient $=0.24, p$-value $=0.000 ; \underline{\mathbf{H 5} .3}$ supported $)$. Results were in support with previous studies, which argued that narcissism and social media addiction are positively correlated ${ }^{[91]}$. Narcissists use social media in a way for self- promoting, which can be seen and identified by others. Therefore, self- promoting and beautiful profile pictures are used by those with a narcissistic personality. Moreover, vulnerable narcissists feel safer and more comfortable in the online environment, than in offline communications and interactions, unlike grandiose narcissists, which to them, SNS is just one of many tools that they can use, to reach their narcissistic goals ${ }^{[92]}$. Furthermore, vulnerable narcissists could be addicted in terms of exposing their information on SNS; to project the image of being perfect, which they have a difficulty in projecting in their offline communications and interactions, unlike grandiose narcissists who can easily promote the image of perfection anytime and anywhere ${ }^{[93]}$.

The results revealed that leisure boredom significantly affected gratifications obtained from SNS (path coefficient $=0.091, p$-value $=0.025 ; \underline{\text { H6.1 }}$ supported $)$. When leisure experiences are not exciting, they are more likely to result in boredom, which is one of the major motives to use social media ${ }^{[86]}$. Social media allows individuals who have nothing to do, to engage in different online activities. SNS games and activities provide a platform for leisurely bored individuals to have fun and pass their time ${ }^{[94]}$. Gratifications offered by social media, especially the entertainment gratification, offer individuals a let out from boredom or stress ${ }^{[95]}$. However, results revealed that leisure boredom insignificantly affected SNS usage ( $\underline{\mathbf{H 6} .2}$ rejected) and SNS addiction ( $\underline{\mathbf{H 6 . 3}}$ rejected), based on previous studies, if users are engaged in and provided with alternatives and supplements to online activities, they might engage in other offline social activities, which would prevent them from logging into social media ${ }^{[94]}$. Moreover, even though SNS helps in relieving feelings of boredom in leisure, through the interpersonal interactions they allow, individuals who are fond of their families, other offline and outdoor leisure activities report lower levels of SNS addiction ${ }^{[38]}$.

Results indicated that social capital was significant with gratifications obtained from SNS (path coefficient= $0.971, p$-value $=0.000 ; \underline{\mathbf{H 7} .1}$ supported). According to preceding studies, it is not the technology itself that affects the individual's social capital, but the way individuals use it, and whether it affects individuals' social capital depends on the reasons behind their usage ${ }^{[43]}$. Individuals use these platforms to both satisfy their hedonic needs and manage their social relationships ${ }^{[96]}$. The results indicated that social capital was also significant with SNS usage (path coefficient $=0.141, p$-value $=0.000 ; \underline{\mathbf{H 7} 7.2}$ supported $)$ and SNS addiction (path coefficient $=0.13, p$-value $=0.003$; H7.3 supported). Social capital can be increased by social media usage ${ }^{[97]}$, and the intensity of social media usage affects the accumulation of interpersonal relationships ${ }^{[98]}$. The main purpose behind SNS is to provide users with the technology that would offer them the ease to build social networks ${ }^{[99]}$, and users who are addicted to social media are more likely to develop stronger ties and relationships with others on these platforms ${ }^{[40,41]}$.

The results revealed that attitudes toward SNS advertising were significant with gratifications obtained from SNS (path coefficient $=0.169, p$-value $=0.000$; H8.1 supported), attitudes toward SNS advertising are strongly influenced by certain gratifications provided by SNS. For example, socialization, communication, and information gratifications provided by SNS may lead to more favorable attitudes toward SNS advertising ${ }^{[100]}$ Attitudes toward SNS advertising were also significant with SNS usage (path coefficient $=0.16, p$-value $=0.000$; H8.2 supported), since the more a consumer is engaged in a magazine, television program, or newspaper, the more likely their evaluation will be favorable to the advertisements embedded. The same case is applicable to social media as an advertising vehicle. The higher the engagement with social media platforms, the more likely the evaluations and the attitudes toward social media advertising are to be positive ${ }^{[101]}$. However, results revealed that attitudes toward SNS advertising were insignificant with SNS addiction ( $\underline{\mathbf{H 8 . 3}}$ rejected). According to previous studies, users who are more dependent or addicted to social media; may only slightly have positive attitudes and perceive social media advertising as effective or interesting. In addition to that, social media addicts may eventually stop responding or even checking these advertisements, especially if these advertisements are repetitive or irrelevant to them ${ }^{[102,103]}$.

\section{Managerial Implications}

Many organizations have a mistaken belief that simply establishing a page on social media and posting information or content occasionally will result in an incremental increase in their sales. However, this is not true, since social media should become an essential and a fundamental part of an organization's overall marketing strategy, to yield full potential ${ }^{[104]}$. 
The study provides valuable insights into the behavioral attitudes of millennials toward SNS advertising, as well as several other usage characteristics, which have previously received limited empirical investigation. SNS should be utilized in a way that would create and strengthen the bond between consumers and firms, and develop trustworthy relationships with users, especially since the high influence SNS has on millennials provides endless opportunities for firms. The next few paragraphs will draw the attention to several concerns regarding the marketing strategies targeted to consumers through SNS.

Tailor SNS Advertising Messages: in order to appeal to millennials who may be difficult to reach or are notoriously fickle, advertisements must be created carefully to be stimulating and interactive. It is not only important for marketers to tailor the way they advertise for their products and services on SNS, but it also important that they understand the reasons that drive individuals to develop favorable attitudes and interact with their advertising messages. This can be achieved by understanding why consumers are using SNS and what they are doing on these platforms in the first place; to be prepared to adapt or alter their SNS advertising strategies in an owing way to the changes that occur in the environment, and to be able to increase the effectiveness of such advertisements. Tailored advertising would persuade consumers through relevance and meaningful content, which would not only make advertisements more appealing and interesting to them but would also create more loyal consumers.

Encourage Millennials to get Involved: since SNS allows users to have a voice, it can serve as valuable feedback for companies to improve, by encouraging the audience to get involved. Marketers should utilize SNS platforms in a proactive way, to achieve their corporate goals, through effective brand building, customer relationship management, and by focusing on enhancing millennials experience, through getting them involved, and paying attention to their feedback, reviews, and recommendations, which would build loyalty, satisfaction, and long-term relationships.

Realize the Benefits of Millennials: millennials have been identified as an important force, which drives the online shopping industry, they use social media to post photos about products and to learn about products/ services ${ }^{[105]}$ and share their opinions and expertise with others. Millennials look to their peers to determine the benefits and merits of products/ services ${ }^{[49]}$ and are more likely to purchase a product if recommended or has been "liked" by their friends on SNS ${ }^{[50]}$. Since results revealed that millennials, who were more gratified by SNS or engaged in higher SNS usage had a larger social capital, marketers can empower them to be more active in the advancement and promotion of their brands. Especially since individuals are more likely to be influenced by an opinion or action of a friend and become interested in purchasing a certain product when suggested by a friend, than when suggested by an anonymous person ${ }^{[106]}$.

Therefore, marketers should make use of millennials enormous influence on their social networks and on other generations as well, by enabling them to be the disseminators of the marketing messages, through e-WOM. Millennials can effectively serve as a positive WOM and e-WOM for brands. E-WOM has supplemented traditional marketing communications and has proven to have a significant impact on consumers' attitude formations, judgments, and decision making. Especially since consumers find practical and emotional benefits in their participation in the e-WOM and believe that these online conversations have a great impact on the products they consider purchasing ${ }^{[107]}$.

\section{Conclusions}

As the usage of SNS expands and develops rapidly, it is more likely to play a more visible role in the lives of many people all around the world ${ }^{[108]}$. This study adopted the $U \& G$ theory and aimed to identify the social and psychological origins of needs, which may result in different patterns of SNS usage, need to obtain certain gratifications or cause SNS addiction. It also investigated the possible consequences of gratifications obtained, SNS usage and SNS addiction on millennials social capital and attitudes toward SNS advertising. The study presented prior research, added knowledge, and directs for future research. The study added new knowledge to marketing theory by shedding light on user behaviors on SNS in digital platforms and is considered one of the first researches to empirically test and demonstrate the SNS addiction phenomenon among millennials in Egypt.

With regards to the study's limitations and direction for future research, the researcher's ability to make causal claims has been limited by the lack of longitudinal studies. Longitudinal studies are necessary when studying individual behavior because they can show the nature of growth and trace the patterns of change. It gives a truer picture of the cause-and-effect relationships over a period of time ${ }^{[109]}$. Second, this study was only conducted on the millennial age group, because millennials are the age group most likely to be affected by this condition, because they are heavy SNS users ${ }^{[110,111]}$. However, SNS has been witnessing an overwhelming popularity over the past years, and SNS addiction might be a phenomenon 
that not only exists among millennials. Therefore, it is also recommended to examine other age groups in future studies.

Third, the study only focused on three SNS platforms (Facebook, Instagram, and YouTube), since they were found to be the most popular SNS platforms with the highest user engagement rates. However, future studies could also identify other SNS platforms used by millennials, to expand the scope and understanding of the whole SNS addiction phenomenon. Fourth, to better uncover the behavior of narcissists on SNS, it is recommended to measure narcissism in more details to see how vulnerable narcissists differ from grandiose narcissists. Finally, this study only investigated millennials attitudes toward SNS advertising in terms of favorability or infavorability. It is also suggested to explore not only their attitudes toward SNS advertising, but to also measure if their attitudes are reflected in their purchasing behavior.

The researcher hopes that the current research would have helped in constructing a foundation for future investigations on SNS issues.

\section{References}

[1] Pahlevan Sharif, S., Yeoh, K.K., 2018. Excessive social networking sites use and online compulsive buying in young adults: the mediating role of money attitude. Young Consumers. 19(3), 310-327.

[2] Hasan, T., Yasir, H., 2016. Am I A Facebook Addict? An Investigation of Facebook Addiction Using Personality Traits through SEM. Journal of Organisational Studies and Innovation. 3(4), 15-30.

[3] Kuss, D.J., Griffiths, M.D., Demetrovics, Z., 2017. Social networking sites and addiction: Ten lessons learned. International journal of environmental research and public health. 14(3), 311.

[4] Bisen, S.S., Deshpande, Y.M., 2018. Understanding internet addiction: a comprehensive review. Mental Health Review Journal. 23(3), 165-184.

[5] Kamal, N.N., Mosallem, F.A.E.H., 2013. Determinants of Problematic Internet Use Among El-Minia High School Students, Egypt. International Journal of Preventive Medicine. 4(12), 1429-1437.

[6] Mubarak, A.R., Quinn, S., 2019. General strain theory of Internet addiction and deviant behaviour in social networking sites (SNS). Journal of Information, Communication and Ethics in Society. 17(1), 61-71.

[7] James, T.L., Lowry, P.B., Wallace, L., Warkentin, M., 2017. The effect of belongingness on obsessive-compulsive disorder in the use of online social networks. Journal of Management Information Systems. 34(2), 560-596.
[8] Mubarak, A.R., Quinn, S., 2017. General Strain Theory of Internet Addiction and Deviant Behaviour in Social Networking Sites (SNS). Journal of Information, Communication and Ethics in Society.

[9] Özad, B.E., Uygarer, G., 2014. Attachment needs and social networking sites. Social Behavior and Personality: an international journal. 42(1), 43S-52S.

[10] Song, I., LaRose, R., Eastin, M.S., Lin, C.A., 2004. Internet gratifications and Internet addiction: on the uses and abuses of new media. Cyberpsychology \& Behavior. 7(4), 384-394.

[11] Weinstein, A., Lejoyeux, M., 2010. Internet Addiction or Excessive Internet Use. American Journal of Drug \& Alcohol Abuse. 36(5), 277-283.

[12] Yen, J., Yen, C., Wu, H., Huang, C., Ko, C., 2011. Hostility in the Real World and Online: The Effect of Internet Addiction, Depression, and Online Activity. Cyberpsychology, Behavior \& Social Networking. 14(11), 649-655.

[13] Quan-Haase, A., Young, A.L., 2010. Uses and gratifications of social media: A comparison of Facebook and instant messaging. Bulletin of Science, Technology \& Society. 30(5), 350-361.

[14] Yang, S., Liu, Y., Wei, J., 2016. Social capital on mobile SNS addiction: A perspective from online and offline channel integrations. Internet Research. 26(4), 982-1000.

[15] Lineberry, Z.X., 2012. Uses and gratifications on social networking sites: Analysis of use and value of social networking sites for three types of social capital on college students. ProQuest Dissertations \& Theses Global. Retrieved from: https://search.proquest.com/docview/1100968197?accountid=120728.

[16] Ruggiero, T.E., 2000. Uses and gratifications theory in the 21 st century. Mass communication \& society. 3(1), 3-37.

[17] Hoffman, D.L., Novak, P.T., 2012. Need Satisfaction from Interacting with People versus Content: The Roles of Motivational Orientation and Identification with Social Media Groups. ACR North American Advances.

[18] Bharucha, J., 2018. Social network use and youth well-being: a study in India. Safer Communities. 17(2), 119-131.

[19] Dunne, Á., Lawlor, M.A., Rowley, J., 2010. Young people's use of online social networking sites-a uses and gratifications perspective. Journal of Research in interactive Marketing. 4(1), 46-58.

[20] Li, Q., Guo, X., Bai, X., Xu, W., 2018. Investigating microblogging addiction tendency through the lens of uses and gratifications theory. Internet Research. 
28(5), 1228-1252.

[21] Yushi, J., Naqvi, M.H.A., Naqvi, M.H., 2018. Using Social Influence Processes and Psychological Factors to Measure Pervasive Adoption of Social Networking Sites: Evidence from Pakistan. Emerging Markets Finance and Trade. 54(15), 3485-3499.

[22] Chen, J.V., Widjaja, A.E., Yen, D.C., 2015. Need for affiliation, need for popularity, self-esteem, and the moderating effect of big five personality traits affecting individuals' self-disclosure on Facebook. International Journal of Human-Computer Interaction. 31(11), 815-831.

[23] Marwick, A., 2005. I'm a lot more interesting than a friendster profile: Identity, authenticity, and power in social networking services. Paper presented at the Conference of Association for Internet Researchers 6, Chicago, IL, United States.

[24] Ong, E.Y., Ang, R.P., Ho, J.C., Lim, J.C., Goh, D.H., Lee, C.S., Chua, A.Y., 2011. Narcissism, extraversion and adolescents' self-presentation on Facebook. Personality and individual differences. 50(2), 180-185.

[25] Zhou, S.X., Leung, L., 2012. Gratification, loneliness, leisure boredom, and self-esteem as predictors of SNS-game addiction and usage pattern among Chinese college students. International Journal of Cyber Behavior, Psychology and Learning (IJCBPL). 2(4), 34-48.

[26] Marín, L., Ruiz de Maya, S., 2013. The role of affiliation, attractiveness and personal connection in consumer-company identification. European Journal of Marketing. 47(3/4), 655-673.

[27] Peter, J., Valkenburg, P.M., 2006. Research note: Individual differences in perceptions of Internet communication. European Journal of Communication. 27(2), 213-226.

[28] Köllner, M.G., Schultheiss, O.C., 2014. Meta-analytic evidence of low convergence between implicit and explicit measures of the needs for achievement, affiliation, and power. Frontiers in Psychology. 5, 826.

[29] Lee, C.C., Chiou, W.B., 2013. Keep logging in! Experimental evidence showing the relation of affiliation needs to the idea of online social networking. Cyberpsychology, Behavior, and Social Networking. 16(6), 419-422.

[30] Jeong, J., Lee, M., 2013. The Effect of Online Media Platforms on Joining Causes: The Impression Management Perspective. Journal of Broadcasting \& Electronic Media. 57(4), 439-455.

[31] Bolino, M.C., Kacmar, K.M., Turnley, W.H., Gilstrap, J.B., 2008. A multi-level review of impression management motives and behaviors. Journal of Man- agement. 34(6), 1080-1109.

[32] Kraemer, N.C., Winter, S., 2008. Impression management 2.0. The relationship of self-esteem, extraversion, self-efficacy, and self-presentation within social network sites. Journal of Media Psychology. 20(3), 106-116.

[33] Gerstner, W., König, A., Enders, A., Hambrick, D.C., 2013. CEO Narcissism, Audience Engagement, and Organizational Adoption of Technological Discontinuities. Administrative Science Quarterly. 58(2), 257-291.

[34] Leung, L., 2013. Generational differences in content generation in social media: The roles of the gratifications sought and of narcissism. Computers in Human Behavior. 29(3), 997-1006.

[35] Mehdizadeh, S., 2010. Self-presentation 2.0: Narcissism and self-esteem on Facebook. Cyberpsychology, behavior, and social networking. 13(4), 357-364.

[36] Panek, E.T., Nardis, Y., Konrath, S., 2013. Mirror or Megaphone?: How relationships between narcissism and social networking site use differ on Facebook and Twitter. Computers in Human Behavior. 29(5), 2004-2012.

[37] Leung, L., 2007. Leisure Boredom, Sensation Seeking, Self-Esteem, Addiction Symptoms, and Patterns of Mobile Phone Use. Conference Papers -- International Communication Association. 1.

[38] Poon, D.C.H., Leung, L., 2011. Effects of narcissism, leisure boredom, and gratifications sought on user-generated content among net-generation users. In Evolving psychological and educational perspectives on cyber behavior. 49-63.

[39] Leung, L., 2008. Leisure boredom, sensation seeking, self-esteem, addiction symptoms and patterns of mobile phone use. In E. Korini, S. Utz, M. Tanis, \& S. B. Barnes (Eds.), Mediated Interpersonal Communication. New York: Routledge. 359-381.

[40] Srivastava, C., Bhardwaj, A., 2014. Adverse Effects of Online Social Networking on Children and Adolescents. Journal of Indian Association for Child \& Adolescent Mental Health. 10(2), 80-92.

[41] Schlachte, C., 2014. Social capital and social media: The effects of Facebook use on social capital and perceived community involvement. ProQuest Dissertations \& Theses Global. Retrieved from: https:// search.proquest.com/docview/1558864316?accountid $=120728$.

[42] Ihm, J., 2018. Social implications of children's smartphone addiction: The role of support networks and social engagement. Journal of behavioral addictions. 7(2), 473-481. 
[43] Valenzuela, S., Park, N., Kee, K.F., 2009. Is There Social Capital in a Social Network Site? Facebook Use and College Students' Life Satisfaction, Trust, and Participation. Journal of Computer-Mediated Communication. 14(4), 875-901.

[44] Glaser, P., Liu, J.H., Hakim, M.A., Vilar, R., Zhang, R., 2018. Is Social Media Use for Networking Positive or Negative? Offline Social Capital and Internet Addiction as Mediators for the Relationship between Social Media Use and Mental Health. New Zealand Journal of Psychology. 47(3).

[45] Bian, M., Leung, L., 2014. Smartphone addiction: Linking loneliness, shyness, symptoms and patterns of use to social capital. Media Asia. 41(2), 159-176.

[46] Knoll, J., 2016. Advertising in Social Media: A Review of Empirical Evidence. International Journal of Advertising. 35(2), 266-300.

[47] Swid, A., 2017. Social Media Advertising: A User' Personality Approach. Journal of International Management Studies. 17(2), 57-62.

[48] Li, J.B., Mo, P.K., Lau, J.T., Su, X.F., Zhang, X., Wu, A.M., Chen, Y.X., 2018. Online social networking addiction and depression: The results from a largescale prospective cohort study in Chinese adolescents. Journal of behavioral addictions. 7(3), 686696.

[49] Smith, K.T., 2012. Longitudinal study of digital marketing strategies targeting Millennials. Journal of Consumer Marketing. 29(2), 86-92.

[50] Iyer, R., Eastman, J.K., Monteiro, H., Rottier, H., Zokarkar, S.S., 2016. Perceptions of Millennials' Media Attitudes and Use: A Comparison of U.S. and Indian Millennials. Marketing Management Journal. 26(2), 69-85.

[51] Duffett, R.G., Wakeham, M., 2016. Social Media Marketing Communications Effect on Attitudes among Millennials in South Africa. African Journal of Information Systems. 8(3), 20-44.

[52] Lujja, A., Ozata, F.Z., 2017. The Consequences of Consumer Engagement in Social Networking Sites. Business and Economics Research Journal. 8(2), 275-291.

[53] Taylor, D.G., Lewin, J.E., Strutton, D., 2011. Friends, fans, and followers: do ads work on social networks?: how gender and age shape receptivity. Journal of advertising research. 51(1), 258-275.

[54] Mir, I.A., 2017. Impact of Entertainment Motivational Drivers on User Acceptance of Online Social Network Banner Advertising: A Gratification Perspective. Zagreb International Review of Economics \& Business. 20(1), 19-47.
[55] Can, L., Kaya, N., 2016. Social networking sites addiction and the effect of attitude towards social network advertising. Procedia-Social and Behavioral Sciences. 235, 484-492.

[56] Griffiths, M.D., Kuss, D.J., Demetrovics, Z., 2014. Social networking addiction: An overview of preliminary findings. In Behavioral addictions. 119-141.

[57] Bányai, F., Zsila, Á., Király, O., Maraz, A., Elekes, Z., Griffiths, M.D., Demetrovics, Z., 2017. Problematic social media use: Results from a large-scale nationally representative adolescent sample. PLoS One. 12(1).

[58] Cabral, J., 2008. Is generation Y addicted to social media. Future of children. 18, 125.

[59] Kuss, D.J., Griffiths, M.D., 2011. Online social networking and addiction - a review of the psychological literature. International journal of environmental research and public health. 8(9), 3528-3552.

[60] Monacis, L., De Palo, V., Griffiths, M.D., Sinatra, M., 2017. Social networking addiction, attachment style, and validation of the Italian version of the Bergen Social Media Addiction Scale. Journal of Behavioral Addictions. 6(2), 178-186.

[61] Andreassen, C.S., Billieux, J., Griffiths, M.D., Kuss, D.J., Demetrovics, Z., Mazzoni, E., Pallesen, S., 2016. The relationship between addictive use of social media and video games and symptoms of psychiatric disorders: A large-scale cross - sectional study. Psychology of Addictive Behaviors. 30(2), 252-262.

[62] Johnson, P.R., 2014. Toward a uses and gratifications model of twitter. ProQuest Dissertations \& Theses Global. Retrieved from: https://search.proquest.com/ docview/1615884122? accountid=120728.

[63] Schönbrodt, F.D., Gerstenberg, F.X., 2012. An IRT analysis of motive questionnaires: The unified motive scales. Journal of Research in Personality. 46(6), 725-742.

[64] Krisanic, K., 2008. Motivations and impression management: Predictors of social networking site use and user behavior. ProQuest Dissertations \& Theses Global. Retrieved from: https://search.proquest.com/ docview/304527436? accountid=120728.

[65] Neria, A.L., 2017. Are narcissists more likely to support terrorism? exploring the relationships between claiming fake religious knowledge and support for violence, peace, and apathy. ProQuest Dissertations \& Theses Global. Retrieved from: https://search.proquest.com/docview/1924790834?accountid=120728.

[66] Kara, F.M., Gurbuz, B., Oncu, E., 2014. Leisure Boredom Scale: the Factor Structure and the Demographic Differences. The Turkish Journal of Sport 
and Exercise. 16(2), 28-35.

[67] Chang, T., Hsiao, W., 2014. Time Spent on Social Networking Sites: Understanding User Behavior and Social Capital. Systems Research \& Behavioral Science. 31(1), 102-114.

[68] Zhang, J., Mao, E., 2016. From online motivations to ad clicks and to behavioral intentions: An empirical study of consumer response to social media advertising. Psychology \& Marketing. 33(3), 155-164.

[69] Azam, A., Qiang, F., Abbas S.A., Abdullah, M.I., 2013. Structural Equation Modeling (SEM) based trust analysis of Muslim consumers in the collective religion affiliation model in e-commerce. Journal of Islamic Marketing. 4(2), 134-149.

[70] Arbuckle, J., Wothke, W., 2004. Structural equation modeling using AMOS: An Introduction.' Retrieved from: https://stat.utexas.edu/images/SSC/Site/ AMOS_Tutorial.pdf.

[71] Savalei, V., Bentler, P.M., 2010. Structural equation modeling. Corsini encyclopedia of psychology. 1-61.

[72] Carter, R.L., 2006. Solutions for Missing Data in Structural Equation Modeling. Research \& Practice in Assessment. 1, 4-7.

[73] Wolf, E.J., Harrington, K.M., Clark, S.L., Miller, M.W., 2013. Sample size requirements for structural equation models: An evaluation of power, bias, and solution propriety. Educational and psychological measurement. 73(6), 913-934.

[74] Schreiber, J.B., Nora, A., Stage, F.K., Barlow, E.A., King, J., 2006. Reporting structural equation modeling and confirmatory factor analysis results: A review. The Journal of educational research. 99(6), 323-338.

[75] Weston, R., Gore J, P.A., 2006. A brief guide to structural equation modeling. The counseling psychologist. 34(5), 719-751.

[76] Purdue Statistics. Structural Equation Modeling: Retrieved from: www.stat.purdue.edu/ bacraig/SCS/ Structural\%20Equation\%20Modeling.doc.

[77] Afthanorhan, W.M.A.B.W., 2013. A comparison of partial least square structural equation modeling (PLS-SEM) and covariance based structural equation modeling (CB-SEM) for confirmatory factor analysis. International Journal of Engineering Science and Innovative Technology. 2(5), 198-205.

[78] Anderson, J.C., Gerbing, D.W., 1988. Structural equation modeling in practice: A review and recommended two-step approach. Psychological bulletin. 103(3), 411.

[79] Hair, J., Black, W., Babin, B., Anderson, R., Tatham, R., 2006. Multivariate data analysis. (6th Ed.). Up- persaddle River, N.J.: Pearson Prentice Hall.

[80] Salman, M., Khan, S., Gul, M.S.A., 2014. Factors Influencing Impulse Buying of Sports Team Merchandise in Developing Country: an Empirical Investigation. Pakistan Journal of Commerce and Social Sciences. 8(1), 185-200.

[81] Hu, L.T., Bentler, P.M., 1999. Cutoff criteria for fit indexes in covariance structure analysis: Conventional criteria versus new alternatives. Structural equation modeling: a multidisciplinary journal. 6(1), 1-55.

[82] John, G., Reve, T., 1982. The reliability and validity of key informant data from dyadic relationships in marketing channels. Journal of marketing research. pp.517-524.

[83] Byrne, B.M., 2001. Structural equation modeling with AMOS: Basic concepts, applications, and programming. Mahwah, NJ: Erlbaum.

[84] El-Kayaly, D., 2012. The Impact of the Three Dimensions of Marketing on the Satisfaction and Loyalty of Clients: An Application to the Branded Car Market in Egypt (Doctoral dissertation, Maastricht School of Management (MSM), Cairo, Egypt).

[85] Liu, Y., 2016. From social media uses and gratifications to social media addiction: A study of the abuse of social media among college students. ProQuest Dissertations \& Theses Global. Retrieved from: https://search.proquest.com/ docview/1806943761 ?accountid=120728.

[86] Huang, H., 2011. Social media addiction among adolescents in urban china: An examination of sociophysiological traits, uses and gratifications, academic performance, and social capital. ProQuest Dissertations \& Theses Global. Retrieved from: https:// search.proquest.com/docview/1018706211?accountid $=120728$.

[87] Gibbs, J., Ellison, N., Heino, R., 2006. Self-presentation in online personals: The role of anticipated future interaction, self-disclosure, and perceived success in Internet dating. Communication Research. 33, 152-180.

[88] Islam, A.N., Mäntymäki, M., Benbasat, I., 2018. Duality of self-promotion on social networking sites. Information Technology \& People.

[89] Czarna, A.Z., Dufner, M., Clifton, A.D., 2014. The effects of vulnerable and grandiose narcissism on liking-based and disliking-based centrality in social networks. Journal of Research in Personality. 50, 4245.

[90] Bergman, S., Fearrington, M., Davenport, S., Bergman, J., 2011. Millennials, narcissism, and social networking: What narcissists do on social networking 
sites and why. Personality and Individual Differences. 50(5), 706-711.

[91] Malik, S., Khan, M., 2015. Impact of facebook addiction on narcissistic behavior and self- esteem among students. J Pak Med Assoc. 65(3), 260-263.

[92] Casale, S., Fioravanti, G., Rugai, L., 2016. Grandiose and vulnerable narcissists: who is at higher risk for social networking addiction?. Cyberpsychology, Behavior, and Social Networking. 19(8), 510-515.

[93] Avant, A., 2017. Examining the impact that the locus of control, emotional intelligence, and narcissism have on internet addiction and information disclosure among college students.

[94] Zhou, Y., 2009. Behavioral versus perceptional dimensions of Social Networking Websites use and their relationship to young adults' social motives, personality, and social well-being. China Computer-Mediated Communication Studies. 3, 27-46.

[95] Apaolaza, V., Hartmann, P., He, J., Barrutia, J.M., Echebarria, C., 2015. Shanghai adolescents' brand interactions on the Chinese Social Networking Site Qzone: A Uses and Gratifications Approach. Revista Española de Investigación de Marketing ESIC. 19, 62-70.

[96] Yuan, C.W.T., 2015. The influences of dual social network site use and social capital development on sociocultural adaptation. ProQuest Dissertations \& Theses Global. Retrieved from: https://search.proquest.com/docview/1730367268?accountid=120728.

[97] Lu, H.P., Lin, C.C., Hsiao, K.L., Cheng, L.T., 2010. Information sharing behavior on blogs in Taiwan: Effects of interactivities and gender differences. Journal of Information Science. 36(3), 401-416.

[98] Guo, Y., Li, Y., Ito, N., 2014. Exploring the predicted effect of social networking site use on perceived social capital and psychological well-being of Chinese international students in Japan. Cyberpsychology, Behavior, and Social Networking. 17(1), 52-58.

[99] Choi, J., Kim, H.J., 2016. Influence of SNS user innovativeness and public individuation on SNS usage patterns and social capital development: The case of Facebook. International Journal of Human-Computer Interaction. 32(12), 921-930.

[100] Chung, C., Austria, K., 2010. Social Media Gratification and Attitude toward Social Media Marketing Messages: A Study of the Effect of Social Media Marketing Messages on Online Shopping Value.
Proceedings of the Northeast Business \& Economics Association. 581-586.

[101] Voorveld, H.A., Van Noort, G., Muntinga, D.G., Bronner, F., 2018. Engagement with social media and social media advertising: The differentiating role of platform type. Journal of Advertising. 47(1), $38-54$

[102] Hudson, A.H., 2016. Exploring the Influence of Social Networking Site Usage on Online Compulsive Buying Behavior and Internet Addiction among US College Students. St. Thomas University.

[103] Leon, M.A., 2017. A Media System Dependency Study of Advertising Consumption Trends on Social Media (Doctoral dissertation, San Diego State University).

[104] Duffett, R.G., 2015. Facebook advertising's influence on intention-to-purchase and purchase amongst Millennials. Internet Research. 25(4), 498526.

[105] Yamawaki, M.A.C., Sarfati, G., 2019. The Millennials Luxury Brand Engagement on social media: A Comparative Study of Brazilians and Italians. Internext: Revista Electrônica de Negócios Internacionais Da ESPM. 14(1), 14-30.

[106] Karimzadehgan, M., Agrawal, M., Zhai, C., 2009. Towards advertising on social networks. Proceedings of the ACM SIGIR workshop on Information Retrieval and Advertising (IRA), Boston, MA, USA. 1-4.

[107] Martínez-Navarro, J., Bigné, E., 2017. The value of marketer-generated content on social network sites: media antecedents and behavioral responses. Journal of Electronic Commerce Research. 18(1), 52.

[108] Mansour, E., 2012. The role of social networking sites (SNSs) in the January 25th Revolution in Egypt. Library Review. 61(2), 128-159.

[109] Rajulton, F., 2001. The fundamentals of longitudinal research: an overview. Canadian Studies in Population. 28(2), 169-185.

[110] Bright, L., Grau, S.L., Kleiser, S.B., 2015. Thumbs Down to Facebook? Exploring Social Media Addiction among Millennials using the Consumption.

[111] Sago, B., 2010. The Influence of Social Media Message Sources on Millennial Generation Consumers. International Journal of Integrated Marketing Communications. 2(2), 7-18. 